\title{
Doralice Maria Cella (1954-2013)
}

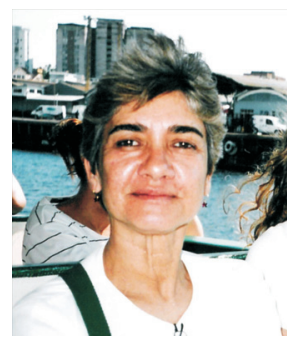

Doralice Maria Cella (or simply "Dora" as she liked to be addressed and will always affectionately be remembered) passed away on February 21, 2013, due to a colon cancer. Dora graduated in Biological Sciences (1978) and concluded her PhD in Zoology (1988) at UNESP, Rio Claro.

Since 1984, she was a Professor at the Biology Departament, Instituto de Biociências, UNESP, Rio Claro. Dora was a benchmark in studies of Cytogenetic of Arthropods, mainly by elucidating and interpreting the chromosomal evolution and mechanisms of differentiation of many sex determination systems. Her studies included analysis and interpretation of autosomal and sex chromosomes behavior, during meiosis. She guided many undergraduate and graduate students, who continue her research work, in different regions of Brazil.
Besides her important role and dedication to research, Dora was a much loved professor, admired and respected by colleagues and students of Biological Sciences Course, and she was chosen by her students as honored or patron speaker Professor during almost all years she taught graduation classes. Her early passing away has caused a lot of sorrow to all friends and colleagues, but her teaching, no doubt, will remain alive in the hundreds of professionals she created along her scientific and academic life.

I miss her and besides all professional learning and love to research and teaching example, I will always have in my heart the assurance of having shared with Dora a great friendship, with all magnitude this feeling may mean.

Marielle Cristina Schneider Departamento de Ciências Biológicas, Universidade Federal de São Paulo, Campus Diadema, Diadema, SP, Brazil. 